\title{
A Forma da Noite: uma proposta de análise formal da Noite Transfigurada
}

\author{
André de Cillo Rodrigues \\ UFRGS \\ andre.cillo@ufrgs.br
}

\begin{abstract}
Resumo: Este artigo investiga a relação entre as resultantes harmônicas e a estruturação formal da Noite Transfigurada, composta por Arnold Schoenberg em 1899. Inicialmente é feito um exame crítico de algumas propostas de segmentação formal da peça a partir dos trabalhos de autores como Swift (1977), Pfannkuch (1963), Frisch (1993) e Wellesz (1968). Posteriormente, o artigo apresenta uma análise formal construída a partir do detalhamento da estruturação harmônica em relação aos materiais temáticos da peça. A análise evidenciou o papel relevante da harmonia na estruturação da peça, além de sua inadequação a modelos formais apriorísticos. Em outras palavras, a análise revelou a existência de um projeto harmônico em que ainda é possível perceber a existência dos mecanismos fundamentais do tonalismo, responsáveis pelo aumento da redundância das relações internas colocadas pela obra nos planos micro e macro estruturais.
\end{abstract}

Palavras-chave: Noite Transfigurada, Schoenberg, Análise Musical, Forma Musical, Harmonia.

\section{The Form of the Night: a proposition of formal analysis of the Transfigured Night}

Abstract: This paper investigates the relationship between harmony and the formal structuring of the piece Transfigured Night, composed by Arnold Schoenberg in 1899. Initially, we review some previous attempts at describing the formal segmentation of the piece by examining the works of authors such as Swift (1977), Pfannkuch (1963), Frisch (1993) and Wellesz (1968). Subsequently, a formal analysis, constructed from the details of the harmonic structuring in relation to the thematic materials of the piece, is proposed. The analysis showed the important role of harmony in the structuring of the piece and its inadequacy in fitting a priori models of structuring musical form. In other words, the analysis revealed the existence of a harmonic project in which it is still possible to perceive the existence of the fundamental mechanisms of the tonal system and its effect in the micro and macrostructure of the piece.

Keywords: Transfigured Night, Schoenberg, Musical Analysis, Musical Form, Harmony.

\section{Introdução}

É quase desnecessário chamar a atenção do melômano mais informado para o fato de que Arnold Schoenberg foi, durante sua vida, o compositor mais combatido de toda a História da Música. Depois de sua morte, acontecimento que em geral inspira ao menos certa cortesia, mesmo aos que não eram muito amigos do falecido, os comentários permaneceram ainda tingidos de um forte antagonismo. (...) sua obra não é muito aceita pelos 'conservadores', que a julgam 'revolucionária' demais, nem pelos 'revolucionários', que a acham muito 'conservadora' (LEIBOWITZ, 1981, p. 29).

De um modo geral, a obra musical de Schoenberg é marcada por profundas contradições que afloram do choque entre o anseio de incorporar a tradição e a sua necessidade de invenção, de dizer "o novo". Seria razoável pensar que o fato de ter crescido em meio a um Sistema Tonal ainda vigente e pouco depois vivenciado tanto seus 
momentos finais quanto seu declínio tenham contribuído para marcar sua obra com esta antinomia que se expressa, por um lado, no respeito profundo à tradição musical germânica e, por outro, na busca incessante por novas soluções composicionais.

No âmbito desta reflexão, o sexteto de cordas Verklärte Nacht (Noite Transfigurada), escrito em 1899, ocupa um lugar especial na primeira fase do compositor (1897-1908) ao representar bastante bem esta tendência dialética de Schoenberg de combinar o velho e o novo em um todo homogêneo. Seus laços com a tradição ficam aparentes através de diversas características composicionais que, de acordo com ele, se articularam a partir da influência e do estudo da obra de outros compositores do período como Franz Liszt, Hugo Wolf, Richard Strauss e, especialmente, Johannes Brahms e Richard Wagner (SCHOENBERG, 1984, p. 80).

Seria possível até mesmo advogar que uma das novidades estabelecidas pela Noite Transfigurada se encontra precisamente na maneira como estas diversas influências confluem e se amalgamam dando vazão a outros elementos tidos como tipicamente schoenbergianos: a complexidade polifônica, os movimentos melódicos que privilegiam notas estranhas aos acordes, saltos intervalares grandes (e as tensões resultantes), a coloração cromática, o ritmo livre (quase que independente do compasso) e a variação no lugar da repetição ou das sequências wagnerianas (STUCKENSCHMIDT, 1959, p. 2526). Afinal, se a conexão com a tradição musical germânica tivesse se refletido apenas em uma repetição estéril de aquisições artísticas e técnicas anteriores, muito provavelmente a estreia da obra, em 1902, não teria sido marcada por inúmeras controvérsias, incluindo vaias e a troca de socos em pleno teatro (SCHOENBERG, 2016, p.129).

\section{Relação com a poesia de Dehmel}

No livro The Early Works of Arnold Schoenberg, Walter Frisch sustenta a hipótese de que o contato com a poesia de Richard Dehmel tenha constituído um fator determinante na busca por um caminho autoral próprio que o distanciasse definitivamente da sombra de Brahms e Wagner: 
Ele haveria de encontrar seu próprio caminho, sua própria voz, na redescoberta dos versos de Dehmel, especificamente na coleção Weib und Welt. O envolvimento de Schoenberg com este volume em 1899 foi tão intenso que acredito que se possa dizer que seu notável desenvolvimento naquele ano, culminando no sexteto Verklärte Nacht, surgiu diretamente de sua busca por uma linguagem musical apropriada à poesia de Weib und Welt $^{1}$ (FRISCH, 1993, p. 80).

O impacto da poesia de Dehmel na obra de Schoenberg parece ter sido considerável, especialmente levando em conta que a quase totalidade das canções para voz e piano que compreendem seus três primeiros opus estão baseadas em textos do poeta. A influência de Dehmel nas primeiras obras de Schoenberg foi reconhecida pelo compositor em uma famosa carta de 13 de dezembro de 1912:

\begin{abstract}
Mal posso dizer o quão contente eu estou em estar finalmente em contato direto com você. Seus poemas tiveram uma influência decisiva em meu desenvolvimento como compositor. Foram eles que, primeiro, me levaram a buscar uma nova sonoridade, de caráter mais lírico. [...] Minhas primeiras tentativas de compor representações para os seus poemas contêm mais daquilo que foi desenvolvido posteriormente em meu trabalho do que algumas de minhas composições posteriores. (SCHOENBERG, 1964, p. $35)$.
\end{abstract}

Assim como suas canções, a composição da Noite Transfigurada também foi inspirada por um poema homônimo de autoria de Dehmel, constituindo um raro caso de música de câmara programática. Ao ouvir a Noite Transfigurada pela primeira vez o poeta declarou:

\begin{abstract}
Ontem a noite eu ouvi sua Noite Transfigurada e seria uma grande omissão da minha parte se eu não lhe agradecesse por este maravilhoso sexteto. Eu pretendia seguir as ideias do meu texto na sua composição, mas fiquei tão encantado com a música que logo me esqueci (DEHMEL apud MUXENEDER, 2021).
\end{abstract}

O poema que inspirou a Noite Transfigurada conta a história de uma mulher andando em uma floresta sob a luz do luar, que diz ao amante que está grávida de outro homem. Ela se entristece por ter engravidado de outra pessoa antes que pudesse conhecer seu verdadeiro amor, mas seu amante a consola dizendo:

\begin{abstract}
Que a criança que você tenha concebido, não seja para sua alma uma preocupação, Oh veja, como o universo brilha tão luminosamente! Há um brilho ao redor de tudo; Você está flutuando comigo sobre um oceano frio, mas um calor interno flui de você para mim, de mim para você. Este calor transfigurará a criança do desconhecido, Você dará à luz a ela para mim, gerada por mim; Você tem trazido luz para dentro de mim, Você tem gerado um filho de mim mesmo (CUETO JÚNIOR, 2017).
\end{abstract}

\footnotetext{
${ }^{1}$ Weib und Welt (a mulher e o mundo) é um conjunto de poemas de R. Dehmel que acabaria por levar o poeta à julgamento em função de seu conteúdo supostamente obsceno e blasfemo.
} 
A estrutura do poema está baseada em cinco estrofes, que representam três personagens distintos: o narrador (estrofes 1, 3 e 5), a mulher (estrofe 2) e o homem (estrofe 4). A partir disto, o poema pode ser interpretado como uma espécie de Rondó em que o tema, representado pelas intervenções do narrador, nunca se repete integralmente, mas vai se transfigurando à medida em que o poema avança. As estrofes do poema possuem tamanhos variáveis que não se repetem. Aquelas que correspondem ao narrador (1, 3 e 5) demonstram uma trajetória constante de diminuição do número de versos: 6,4 e 3 versos respectivamente, cuja soma total é de 13 versos. A estrofe correspondente à personagem da mulher soma 12 versos e a do homem 11 e também demonstra a mesma estratégia de diminuição ${ }^{2}$.

Também seria possível segmentar o poema em duas partes: a primeira compreendendo a primeira intervenção do narrador, de caráter introdutório, e a estrofe correspondente à personagem feminina e a segunda parte compreendendo a segunda intervenção do narrador, que funciona como uma transição/introdução, somada à estrofe correspondente à personagem masculina. A última intervenção do narrador funcionaria à maneira de uma Coda ou de um posfácio.

\title{
Algumas propostas de análise formal da Noite Transfigurada
}

Tanto Carl Dahlhaus quanto Egon Wellesz interpretam a forma musical da Noite Transfigurada como um rondó subdividido em cinco partes (ABA'CA'), que seriam análogas à estruturação em cinco estrofes do poema de Dehmel que a inspirou. De acordo com Wellesz:

\begin{abstract}
A estrutura da Verklärte Nacht, em conformidade com o poema, é composta por cinco seções, em que a primeira, a terceira e a quinta são de natureza mais épica e, deste modo, retratam os profundos sentimentos das pessoas que vagam pela noite fria e enluarada. O segundo contém a queixa apaixonada da mulher e o quarto a resposta sustentada do homem, que mostra muita profundidade e calor da compreensão (WELLESZ, 1968, p. 67).
\end{abstract}

A relação do poema com a estruturação da peça, entretanto, não é tão direta quanto as considerações analíticas acima poderiam fazer crer. Por um lado, a utilização de textos na composição musical tem a capacidade de fornecer uma direção para a forma musical

\footnotetext{
${ }^{2}$ Seria possível dizer que a assimetria no número de versos do poema vai se refletir musicalmente no tamanho assimétrico das frases que compõem os temas de Schoenberg.
} 
ao propor recortes e continuidades, por outro, no caso da Noite Transfigurada, ao se tratar de uma peça puramente instrumental, o texto permeia a obra in absentia, sem que seja declamado de fato. Na prática, isto vai significar que as relações de sincronicidade entre a estrutura poética e a estrutura musical não possuem um caráter unívoco sequer como proposta composicional e, assim, é muito provável que diferentes analistas divirjam na hora de apontá-las.

Para o próprio Schoenberg, a escuta da obra prescinde do conhecimento prévio do poema de Dehmel ou de sua possível relação:

\begin{abstract}
Minha composição foi, talvez, um tanto diferente de outras composições programáticas. Em primeiro lugar, por não ser uma peça para orquestra, mas para um grupo camerístico; em segundo, pelo fato de não ilustrar uma ação ou drama, mas se restringir a retratar a natureza e a expressão dos sentimentos humanos. Me parece que, em vista desta atitude, minha composição ganhou qualidades que também podem satisfazer aquele que ignora o que ela ilustra, em outras palavras, oferece a possibilidade de ser apreciada como música 'pura' (SCHOENBERG, 2016, p. 124).
\end{abstract}

Neste mesmo texto, Schoenberg indica algumas relações entre música e poesia que fundamentaram a composição da peça, mas, ainda que aceitemos as sugestões de associação indicadas por Schoenberg, é preciso reconhecer que as relações entre temas e seções musicais da Noite Transfigurada com os versos do poema tangenciam aspectos simbólicos e permanecem, portanto, ligadas ao campo da subjetividade, em maior ou menor grau. Por esta razão, a análise de Wellesz, ainda que possa fornecer uma explicação para a subdivisão da peça em grandes partes através do estabelecimento de relações entre a estruturação da peça com a estruturação do poema de Dehmel, não incorpora totalmente os detalhes da complexa teia de relações que perfazem a microestrutura da obra. Outra questão que se coloca na análise da Noite Transfigurada como um rondó é o papel que as partes ocupam no todo. Se a parte A corresponde ao narrador e as partes B e C correspondem, respectivamente, à mulher e ao homem, isto significa que o tema, supostamente mais importante do ponto de vista formal tradicional, cabe ao narrador, enquanto as duas personagens que compõem o poema seriam meros contrastastes (coplas?).

Além disto, é preciso reconhecer que a análise da forma da Noite Transfigurada impõe certos desafios que são inerentes à sua duração ${ }^{3}$, relativamente extensa, às

\footnotetext{
${ }^{3}$ A peça possui 418 compassos e sua interpretação costuma oscilar entre 28 e 32 minutos.
} 
complexas relações harmônicas que são estabelecidas em seu interior e à enorme quantidade de temas e seções em que a peça se reparte. É extremamente difícil a aquisição de uma noção do todo que permita o estabelecimento de considerações de cunho abrangente a respeito da maneira como a peça se organiza, sob pena de simplificarmos demasiadamente a riqueza das relações microestruturais propostas pelo compositor. Estas dificuldades ajudam a explicar a grande quantidade de propostas distintas de análise formal divergentes, em maior ou menor grau, que foram se somando ao longo dos anos. Existem visões muito variadas a respeito do assunto que podem ser observadas em Swift (1977), Pfannkuch (1963), Frisch (1993), Eason (2019), Pedneault-Deslauriers (2015), além dos já mencionados trabalhos de Dahlhaus (1987) e Wellesz (1968), apenas para citar alguns.

Muito possivelmente é a esta complexidade de apresentação e concatenação das ideias que Webern alude ao afirmar que a Noite Transfigurada tinha a forma de uma livre fantasia (frei phantasierend):

O sexteto possui um movimento único, a forma desse movimento é a de uma livre fantasia. A abundância de temas e seu desenvolvimento revelam imediatamente a grande arte de Schoenberg. No que se refere à brevidade dos temas, sua independência e à arquitetura livre resultante dessa música, o sexteto já é uma premonição das obras atuais de Schoenberg. Em termos de novos efeitos melódicos e harmônicos, sobressaiu-se a todos no momento de sua criação; as sonoridades são um milagre sem precedentes na música de câmara. Cito um tema dela, abaixo, que já contém um prenúncio de todas as características próprias da melodia de Schoenberg. Notas "estranhas à harmonia" e sequências cromáticas apontam com clareza o caminho para o distanciamento sempre progressivo da tonalidade, algo que, nas obras atuais de Schoenberg, se consumou totalmente. Além disso: o ritmo livre e flutuante, para o qual a barra de compasso é completamente irrelevante (WEBERN, 1912, p. 23, tradução nossa ${ }^{4}$ ).

A possibilidade concreta de que sua estruturação tenha sido majoritariamente fruto de um esforço intuitivo de Schoenberg e não de um planejamento consciente e racional por parte do compositor, corrobora com esta tese. Segundo um depoimento do próprio compositor, a Noite Transfigurada teria sido escrita de modo espontâneo e muito

\footnotetext{
${ }^{4}$ Das Sextett ist einsätzig, die Form dieses Satzes frei phantasierend. Der Ueberreichtum an Themen und deren Verarbeitung offenbaren sogleich die grosse Kunst Schönbergs. In der Kürze der Themen, ihrer ungebundenen Ablösung und der so entstehenden freien Architektonik dieser Musik, ist das Sextett bereits eine Vorahnung der heutigen Werke Schönbergs. An neuen melodischen und harmonischen Wirkungen überragt es zur Zeit seiner Entstehung alles; im Klang ist es ein Wunder und ohne jedes Vorbild in der Kammermusik. Ich zitiere ein Thema daraus, das im Keime schon alle für Schönbergs Melodik so charakteristischen Merkmale enthält. Harmoniefremde Töne, chromatische Folgen geben deutlich die Richtung zu der immer fortschreitenden und in Schönbergs heutigen Werken gänzlich erfolgten Loslösung von der Tonalität. Ausserdem: die freie, schwebende Rhythmik, für die der Taktstrich ganz belanglos ist.
} 
rapidamente, em apenas três semanas, no mês de setembro de 1899 (MUXENEDER, 2021) ${ }^{5}$. Em notas analíticas publicadas em 1932 e intituladas Konstruktives in der Verklärten Nacht, Schoenberg sugere, novamente, que seu processo de criação teria sido em grande parte espontâneo e que ele não teria tido, portanto, plena consciência das relações harmônicas, motívicas e estruturais que se estabelecem no decorrer da peça (SCHOENBERG, 1932) ${ }^{6}$. A visão de Webern, ainda que parcialmente respaldada por Schoenberg, não se propõe a explicar qual a forma musical que efetivamente decorre da estruturação dos materiais sonoros na peça.

Alguns autores procuraram buscar na relação entre a harmonia e a forma o fundamento da construção da Noite Transfigurada. Pfannkuch (1963) e Swift (1977), cada qual a seu modo, identificam a Noite Transfigurada como uma peça que se estrutura como uma forma-sonata. Por essência, a visão da Noite Transfigurada como uma formasonata implica em considerar-se o planejamento harmônico como um fator essencial no estabelecimento do significado das partes em sua relação com o todo, algo que é de suma importância no caso presente. Em contrapartida, ambas as propostas parecem se equivocar ao tentarem adaptar o conteúdo musical da Noite Transfigurada a uma forma estabelecida aprioristicamente e não verdadeiramente como resultado de suas observações analíticas.

A análise de Pfannkuch, por exemplo, vê a Noite Transfigurada como um movimento único em forma sonata projetado sobre uma estrutura em quatro movimentos - como ocorre na Sonata em Sí menor de Liszt. No entanto, existem inconsistências em sua análise que são referentes justamente à relação entre a harmonia e a estrutura do material musical, que não corresponde adequadamente com aquela que se espera de uma peça em forma-sonata: o conjunto de temas A indicado por ele ignora a existência de temas importantes fora da região de tônica; a transição para o tema $\mathrm{B}$ inclui temas relevantes que são estáveis harmonicamente; e o conjunto de temas B inclui seções

\footnotetext{
${ }^{5}$ Ao discutir o provável período de composição da peça, Walter Frisch sustenta que a hipótese mais lógica seria supor que o sexteto teria sido concebido rapidamente em setembro de 1899 e depois revisado de modo intermitente durante o Outono. Entretanto, ele também levanta a hipótese de que a peça possa ter passado por grandes revisões até sua estreia em 1902 ou, até mesmo, até a sua publicação em 1905 (Frisch, p. 110). ${ }^{6}$ Esta afirmação foi parcialmente contestada pela bibliografia (veja, por exemplo, Shawn, 2003, p. 12-22) e existem muitos indícios de que o compositor possuía um grau elevado de consciência da inter-relação dos materiais musicais da Noite Transfigurada em seus escritos analíticos posteriores (SCHOENBERG, 1984, p. 79-82).
} 
instáveis, tornando sua separação para a seção de desenvolvimento, no mínimo, discutível.

Já o trabalho de Swift identifica a Noite Transfigurada como uma forma que se reparte em duas formas-sonata inter-relacionadas e acrescidas de uma introdução, uma transição (ligando as duas sonatas) e uma Coda. A crítica de Frisch a estes trabalhos é bastante contundente, de modo que remetemos o leitor ao trecho em que este autor analisa estas respectivas proposições (1993, p. 113-116). Em seu texto, Frisch enfatiza os problemas do trabalho de Swift de maneira bastante pormenorizada, o que nos abstém de maiores comentários.

A maior fragilidade dos dois trabalhos discutidos acima não está, evidentemente, na investigação da forma a partir da relação entre o material da peça e seu planejamento harmônico, e sim, no fato de que eles procuram enquadrar a obra em um molde préconcebido ao invés de realmente investigarem aquilo que a peça transmite por si mesma. Sendo assim, mesmo reconhecendo a importância destas contribuições na construção de uma melhor compreensão da peça, o presente texto apresenta uma estratégia distinta de avaliação formal da Noite Transfigurada.

Em lugar de uma busca que parta de uma estruturação formal pré-existente ou mesmo de principiar a análise pela identificação das partes maiores e então identificar sua subsequente divisão em partes menores, propõe-se aqui o oposto: partir da menor subdivisão formal possível, sem uma estruturação ampla à vista, e avaliar simultaneamente o comportamento harmônico e os temas apresentados, na expectativa de que eles possam revelar estruturas maiores e, eventualmente, a organização macroestrutural da obra.

\section{Relações entre os temas}

A despeito de sua complexidade formal, a peça trabalha com um jogo constante entre a ideia de unidade e a ideia multiplicidade que pode ser observado na abundância de materiais musicais distintos que são apresentados no seu decorrer, mas que, no entanto, parecem se conectar tão naturalmente uns com os outros que "é quase desconcertante observá-los mais de perto e perceber o quão imensamente sutis são suas conexões" (SHAWN, 2003, p. 18). 
A conexão entre os diferentes temas não parece ser suficiente, entretanto, para mitigar a dificuldade de observação da macroestrutura da Noite Transfigurada, já que estes temas são muitas vezes apresentados em simultaneidade uns com os outros ou são completamente transformados em seu conteúdo intervalar, rítmico e/ou textural para darem origem a novas ideias e seções formais. Na Noite Transfigurada existem 22 temas principais, que podem ser vistos na tabela abaixo (incluindo o compasso que marca sua primeira aparição na peça):

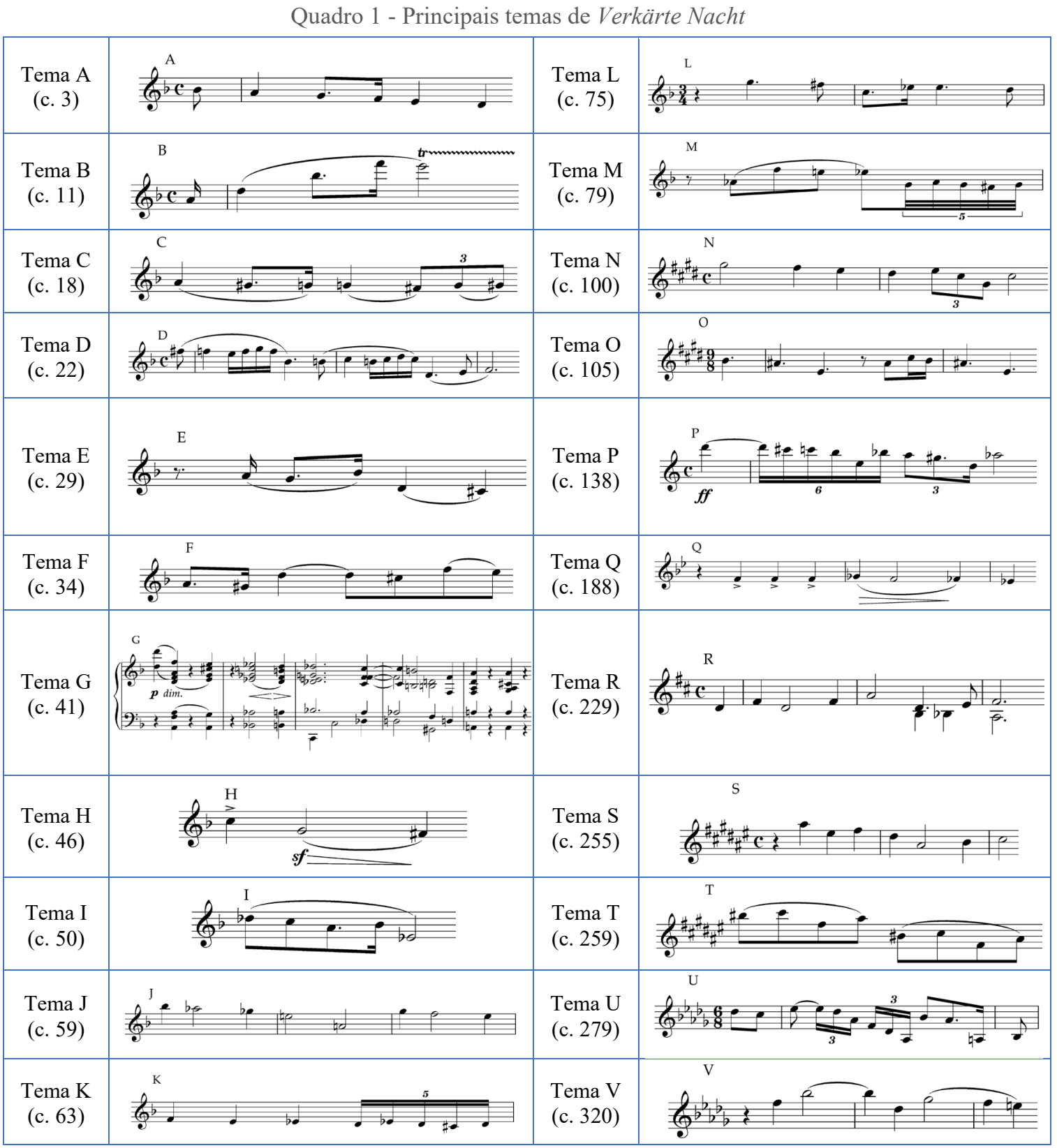

Fonte: Elaboração do autor. 
Estes temas muitas vezes aparecem variados e amalgamados, embora mantenham sua identidade no decorrer da peça. Além disto, eles apresentam relações motívicas entre si, contribuindo para a fluência da obra. Em última instância, estes materiais temáticos utilizados pelo compositor podem ser decompostos em alguns poucos motivos intervalares básicos: o semitom, que aparece tanto isoladamente (motivo a) quanto precedido e/ou sucedido por salto ( $b^{1}$ e $b^{2}$, respectivamente); fragmentos escalares na mesma direção $(c)$; arpejos na mesma direção $(d)$; e a dupla bordadura $(e)$, como mostra a imagem abaixo:

Figura 1: motivos melódico-intervalares

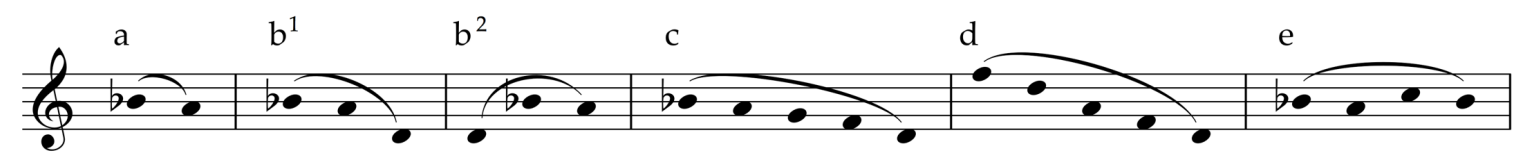

Fonte: Elaboração do autor.

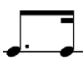


Figura 2: finais dos temas D, J, R e X.
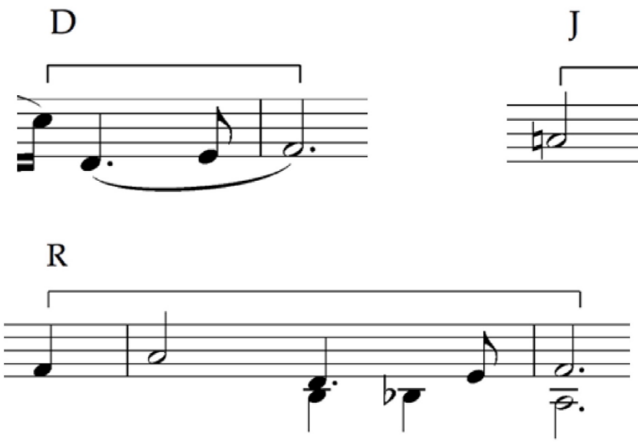

$\mathrm{X}$

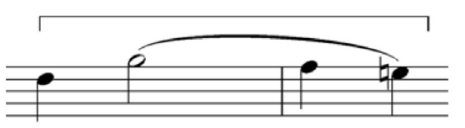

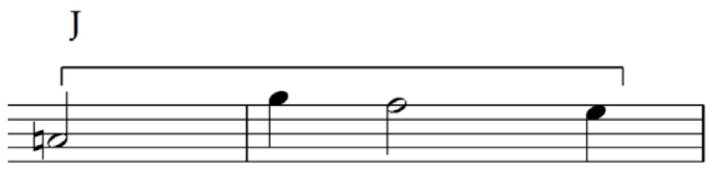

$\mathrm{S}$

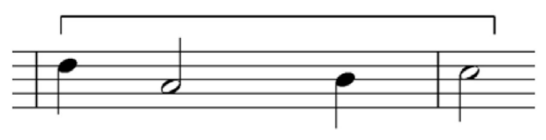

Fonte: elaboração do autor

Os motivos e temas são muitas vezes alterados em seu conteúdo harmônico/intervalar e rítmico por meio do uso de recursos como a aumentação, diminuição, inversão e/ou retrogradação. O movimento em ziguezague da dupla bordadura que surge no tema do compasso 18, por exemplo, tem seus intervalos expandidos impregnando os temas dos compassos 22, 229, 249, 378, 391 e a segunda parte do tema que se inicia no compasso 100. Abaixo, à guisa de exemplificação destas relações, uma comparação entre a ocorrência deste motivo $(e)$ em diferentes momentos da peça:

Figura 3: perfil melódico de excertos dos compassos 22, 249 e 391 da Noite Transfigurada.
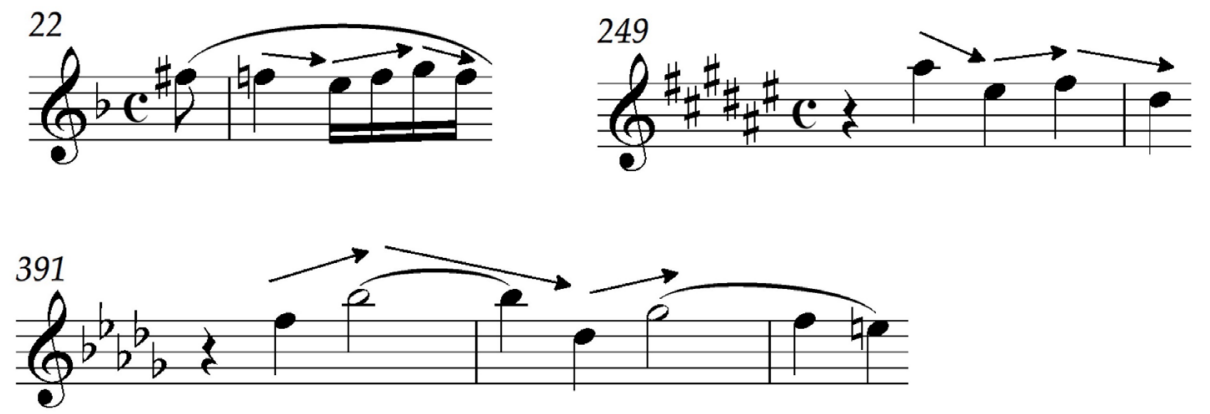

Fonte: elaboração do autor

Pensar em uma proposta de divisão formal levando em conta apenas a organização dos temas e suas texturas dificilmente traria luz à estruturação da forma em grandes partes. São muitas ideias, muitas vezes presentes por alguns poucos compassos e 
apresentadas polifonicamente umas às outras ou, ainda, em variação constante. Tomemos o início como exemplo: a peça apresenta um primeiro tema (tema A, nos cs. 1-10) cuja repetição variada (cs. 13-17) é intercalada por um tema contrastante (tema B, nos cs. 1112), formando uma estrutura ABA. Esta última aparição do tema A (cs. 13-17) é seguida por dois novos temas contrastantes, C (cs. 18-21) e D (cs. 22-23), antes de retornar nos cs. 24-28:

Quadro 2: relação de temas dos primeiros 28 compassos da Noite Transfigurada.

\begin{tabular}{|c|c|}
\hline Tema & Compassos \\
\hline A & 01 a 10 \\
\hline B & 11 a 12 \\
\hline A & 13 a 17 \\
\hline C & 18 a 21 \\
\hline D & 22 a 23 \\
\hline A & 24 a 28 \\
\hline
\end{tabular}

Fonte: elaboração do autor

A partir da configuração formal deste início, uma suposição viável seria a de que a Noite Transfigurada se articula como um rondó em que o tema inicial (refrão) vai sendo intercalado à diversos contrastes (copla). Seria uma hipótese sólida, se depois deste início o compositor não nos apresentasse uma série de novos temas e materiais sem que houvesse sequer uma ocasião em que o retorno do tema A se efetuasse entre eles. Do compasso 29-68 são apresentados nada menos do que 8 novos temas em sequência:

Quadro 3: relação de temas da Noite Transfigurada (compassos 29-62).

\begin{tabular}{|c|c|}
\hline Tema & Compassos \\
\hline E & 29 a 33 \\
\hline F & 34 a 40 \\
\hline G (cadência estendida) & 41 a 45 \\
\hline H & 46 a 49 \\
\hline I & 50 a 57 \\
\hline J & 58 a 62 \\
\hline K (C) & 63 a 66 \\
\hline I1 (motivo inicial) & 67 a 68 \\
\hline
\end{tabular}

Fonte: elaboração do autor 
E, no trecho que vai dos cs. $69-118$, estes temas se somam a mais 4 novos temas e se intercambiam para formar diversas seções da peça antes do retorno de A, que ocorre somente no compasso 119.

\begin{tabular}{|c|c|c|}
\hline & Tema & Compassos \\
\hline & $K(C)+I$ & 69 a 71 \\
\hline & $J+K(C)$ & 71.5 a 74 \\
\hline & $\mathrm{L}$ & 75 a 78 \\
\hline & $M(C)$ & 79 a 80 \\
\hline & L & 83 a 86 \\
\hline & $M(C)$ & 87 a 90 \\
\hline & L & 91 a 97 \\
\hline & 1 & 98 a 99 \\
\hline & $\mathrm{N}$ & 100 a 104 \\
\hline & 0 & 105 a 110 \\
\hline & $M(C)$ & 111 a 112 \\
\hline & 0 & 115 а 118 \\
\hline
\end{tabular}

Fonte: elaboração do autor

O retorno do tema $\mathrm{A}$, a propósito, não se apresenta de maneira muito satisfatória do ponto de vista de sua rememoração, visto que ele é apresentado por inversão e simultaneamente a outros temas, dificultando sua percepção.

Apesar de termos nos dedicado a apenas cerca de 1/4 da obra até o momento, é possível percebermos o quão intrincada parece ser sua forma quando analisada somente a partir da inter-relação dos materiais musicais. São inúmeras as seções, algumas bastante breves e a repetição musical ocorre quase somente a partir das variações dos motivos comuns aos diversos temas. Como veremos adiante, é possível subdividir a Noite Transfigurada em partes maiores, como propôs Wellesz, desde que consideremos a interrelação dos temas musicais como insuficiente para determinar a forma por si só. A seguir, veremos como a harmonia toma parte na construção formal da Noite Transfigurada e como ela pode nos ajudar a entender melhor esta questão. 


\section{Considerações a respeito da harmonia na Noite Transfigurada}

Durante o Romantismo, a utilização de acordes provenientes do campo harmônico maior em peças em tom menor e vice-versa tornou-se um dado corrente da linguagem musical $^{7}$. Na Noite Transfigurada, no entanto, a caracterização destes modos costuma se estabelecer com relativa clareza, de modo a ilustrar o conteúdo semântico do poema. Musicalmente, a transfiguração do pessimismo da mulher no otimismo do amante ocorre com a transformação dos temas em tonalidades menores e altamente cromáticos, que predominam na primeira parte da peça, em temas análogos em tonalidades maiores (mais diatônicos), que predominam na segunda. São inúmeros os casos de emprego deste procedimento, como mostram os excertos abaixo:

Figura 4: Comparação entre temas da Verklärte Nacht. À esquerda os temas da primeira parte e à direita os da segunda

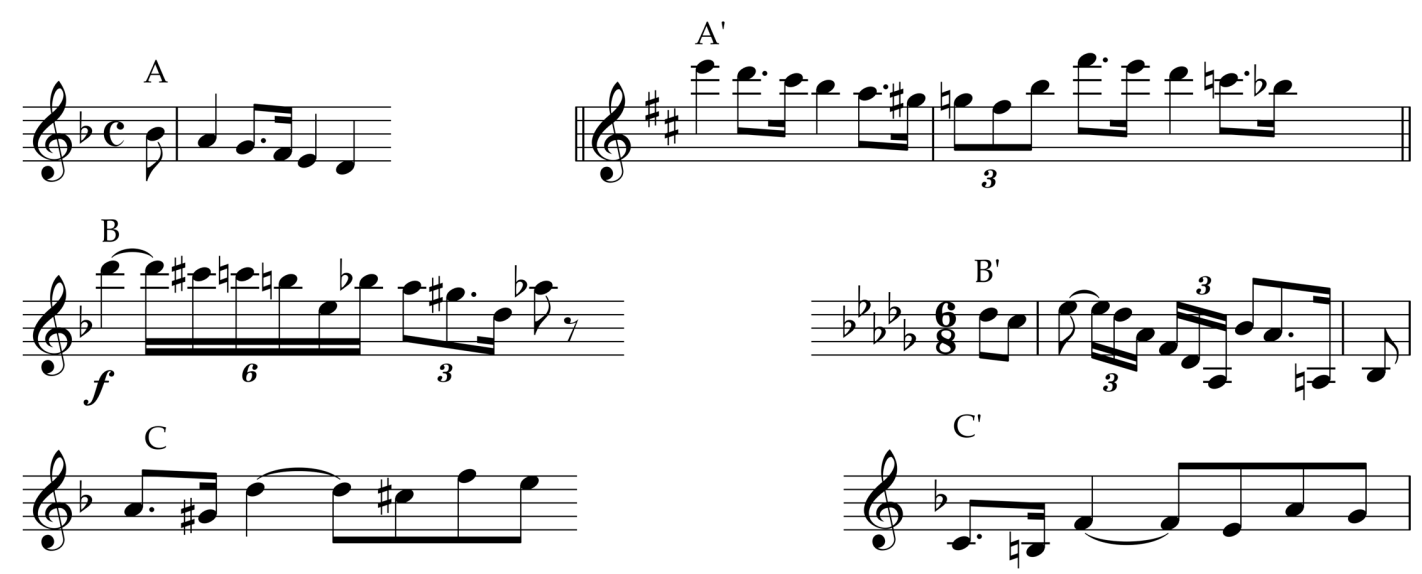

Fonte: Elaboração do autor.

Apesar dos muitos momentos expandidos do ponto de vista da utilização de alterações dos graus do campo harmônico e do uso de acordes vagantes, a harmonia ainda cumpre um papel importante na diferenciação das partes e na configuração

\footnotetext{
${ }^{7} \mathrm{~A}$ ampliação do campo harmônico através da utilização de acordes do campo harmônico menor no maior e vice-versa se tornou tão própria da linguagem Romântica que levou Hauptmann (2014), um teórico do século XIX, a propor a existência de um único modo: o maior-menor, que englobava os acordes destes dois campos harmônicos. O próprio Hugo Riemann, cuja teoria da harmonia funcional foi extremamente influenciada pelo trabalho de Hauptmann, chegou a incorporar esta ideia à sua teoria funcional adaptandoa ao afirmar que qualquer acorde poderia ser seguido por qualquer outro (RIEMANN, 1886); na prática, isto significou absorver, no campo harmônico maior, os acordes relacionados com a tônica menor, subdominante menor e demais regiões. Schoenberg trata especificamente da ampliação do campo harmônico e das possibilidades modulatórias no capítulo VII de Funções Estruturais da Harmonia, cujo título é: Permutabilidade entre Maior e Menor (SCHOENBERG, 2004).
} 
macroestrutural da forma da Noite Transfigurada, mantendo certos princípios caros ao tonalismo como, por exemplo, a necessidade de um estabelecimento claro da tônica no início e no final da obra e a separação entre momentos de estabilidade (existência de centros tonais claros) e de instabilidade harmônica (em que a harmonia se encontra em trânsito).

Um exemplo verificável desta relação entre a harmonia e planejamento formal da obra é a soma das seções na tônica (em número de compassos), que compreende 118 compassos dos 418 que totalizam a peça (26\% aprox.). São, mais especificamente, 24 compassos em Ré menor (5,75\%), que ocorrem na parte inicial da peça, e 92 compassos em Ré maior (20\%), que ocorrem na parte final. Na interpretação do Hollywood String Quartet (SCHOENBERG, 1950), que consiste na primeira gravação da obra, feita sob a supervisão do compositor, os andamentos ajudam a valorizar ainda mais os momentos na tônica, que compreendem, somados, a mais de um terço da duração total da composição:

Quadro 5: proporção temporal entre momentos na tônica e a duração total da peça (interpretação do Hollywood String Quartet).

\begin{tabular}{|l|l|}
\hline Duração Total da obra & $28 ' 39 "$ \\
\hline $\begin{array}{l}\text { tempo total em Ré } \\
\text { menor }\end{array}$ & $2^{\prime} 14^{\prime \prime}(7,9 \%)$ \\
\hline tempo total em Ré Maior & $\begin{array}{l}7^{\prime} 46^{\prime \prime} \\
(27,1 \%)\end{array}$ \\
\hline $\begin{array}{l}\text { Soma das seções em Ré } \\
\text { maior e menor }\end{array}$ & $\begin{array}{l}10^{\prime} 00^{\prime \prime} \\
(34,9 \%)\end{array}$ \\
\hline
\end{tabular}

Fonte: elaboração do autor

Outro exemplo é a valorização da região da relativa maior da tônica menor (tR), isto é, da região de Fá maior (as vezes amalgamado a Fá menor), que aparece em 28 compassos (6,7\% do total). Na gravação do Hollywood Quartet as seções em Fá correspondem a um percentual ainda maior do total da gravação, 8,5\% do total $\left(2{ }^{\prime} 45^{\prime}\right.$ ', em duração). Note-se ainda, que a maior parte das seções em Fá, relativa da tônica menor, ocorre no final da obra, mais próximas de seções em regiões relacionadas a Ré maior (tônica maior) do que Ré menor.

Além disso, o estabelecimento da tônica no início da peça é feito através de um pedal do I grau, que reforça sua estabilidade como centro. As duas primeiras regiões 
modulatórias para as quais a peça se encaminha são, respectivamente, lá menor (v menor, c. 13) e sol menor (subdominante menor, c. 18) e o primeiro tema de maior relevância, depois do tema inicial, surge no compasso 22 na região de Fá, relativa Maior da tônica menor (tema D). Um momento de instabilidade harmônica baseado no tema A (uma ponte!) - durante os cs. 24-28 - nos leva de volta a Ré menor e, após a apresentação de dois novos temas (E e F), tem início um tema coral. Apesar de seu caráter homofônico, em contraposição ao caráter melódico dos demais temas, este tema trabalha com os mesmos motivos apontados anteriormente. A figura abaixo revela alguns deles à guisa de exemplificação:

Figura 5: tema G (análise motívica parcial).

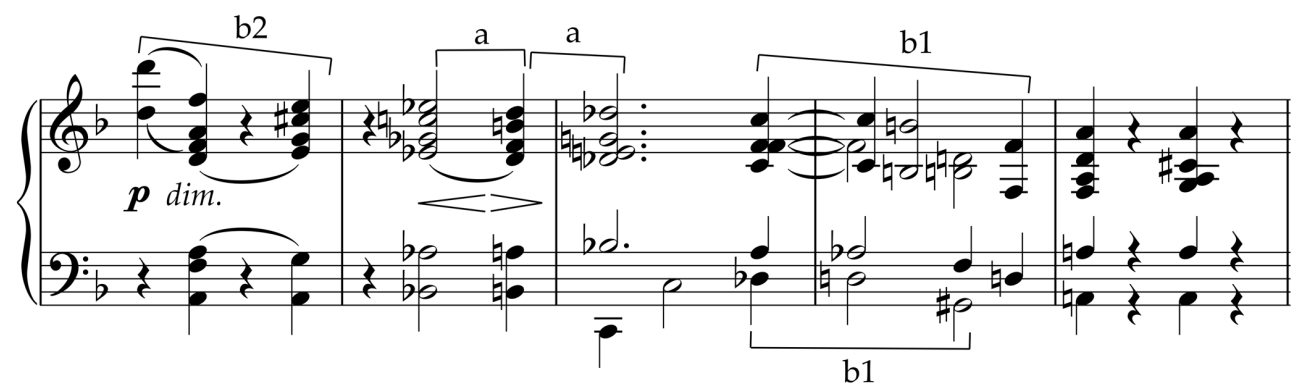

Fonte: elaboração do autor

A apresentação de mais um tema, em Sol menor, no compasso 46, encerra a primeira parte da obra. Até o momento, o esquema harmônico se manteve relativamente simples, se concentrando em regiões harmônicas próximas da tônica. Chama a atenção o fato de que são apresentados nada menos do que 8 materiais temáticos, ainda que com graus diferentes de importância no contexto macroestrutural:

Quadro 6: Análise formal da primeira parte da Noite Transfigurada.

\begin{tabular}{|c|c|c|c|}
\hline Harmonia & Tema & Compassos & Região \\
\hline d & A & 01 a 10 & t \\
\hline d & B & 11 a 12 & t \\
\hline a & A & 13 a 17 & v \\
\hline g & C & 18 a 21 & sd \\
\hline F & D & 22 a 23 & M \\
\hline Instável (F-d) & A & 24 a 28 & $x$ \\
\hline d & E & 29 a 33 & t \\
\hline d & F & 34 a 40 & t \\
\hline
\end{tabular}




\begin{tabular}{|c|c|c|c|}
\hline instável (d-g) & G (cadência estendida) & 41 a 45 & x \\
\hline $\mathrm{g}$ & $\mathrm{H}$ & 46 a 49 & $\mathrm{sd}$ \\
\hline
\end{tabular}

Fonte: elaboração do autor

Na tabela acima, a indicação das regiões harmônicas segue a nomenclatura proposta por Schoenberg em funções estruturais da harmonia (Schoenberg, 2011) e se refere às regiões em modo menor. Uma segunda etapa da peça tem início no compasso 50 com a introdução de mais um tema (Tema I). Ao contrário do que havia acontecido anteriormente, este tema está em uma região distante da tônica, Sib menor, submediante menor da tônica menor na nomenclatura de Schoenberg. Até o compasso 99, quando se encerra esta parte da peça, o compositor passa por outras regiões distantes da tônica com a breve exceção de um momento na subdominante menor nos compassos 77-78-e apresenta mais seis novos temas. É marcante a relação entre os temas $C$, que havia aparecido na seção anterior (c. 18), e os temas K e M, que parecem ser variações do primeiro em ordem progressiva de distanciamento temático ${ }^{8}$ :

Figura 6: Relação sentencial entre temas (variação em desenvolvimento).
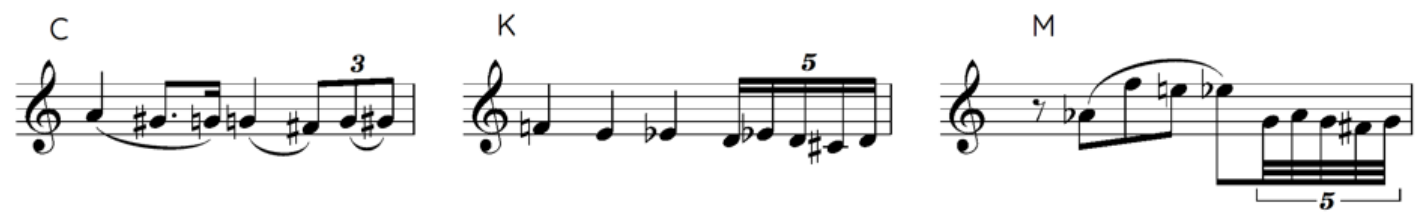

Fonte: elaboração do autor

Se olharmos para a tabela a seguir, que explicita as relações entre a disposição do material temático e a harmonia, fica claro como esta seção se articula através de uma

\footnotetext{
${ }^{8}$ A ideia de que os materiais temáticos se originam a partir da variação de unidades musicais anteriores constitui, resumidamente, aquilo que Arnold Schoenberg descrevia como Variação em Desenvolvimento ou Variação Progressiva. A Variação em Desenvolvimento constitui uma categoria especial da técnica de variação que implica em um processo teleológico (HAIMO, 1997, p. 351) em que a variação das características de uma unidade básica produz "todas as formulações temáticas que propiciam fluência, contraste, variedade, lógica e unidade, por um lado, e as qualidades, a disposição, a expressão e cada necessidade de diferenciação, por outro lado, assim elaborando a ideia de uma peça" (SCHOENBERG, 1984, p. 397). Ainda que não seja possível abordar o conceito detalhadamente neste artigo é importante chamar atenção para o fato de que a Variação Progressiva constitui um dos principais recursos composicionais utilizados por Schoenberg na escrita da Noite Transfigurada, juntamente com a ideia Wagneriana de modelo e sequência. Segundo Schoenberg: “(...) na minha Noite Transfigurada a construção temática se baseia no modelo Wagneriano de modelo e sequência, por um lado, e na técnica Brahmsiana de Variação em Desenvolvimento - como eu a chamo - por outro lado" (SCHOENBERG, 1984, p. 80).
} 
harmonia de caráter mais instável em relação à primeira parte da obra. É importante observar que algumas das regiões pelas quais a obra passa não constam na proposta do quadro de regiões em modo menor proposto por Schoenberg em Funções Estruturais, de modo que as indicações em azul se referem a regiões relacionadas à tônica maior (Ré Maior):

Quadro 7: Análise formal da segunda parte da Noite Transfigurada.

\begin{tabular}{|c|c|c|c|}
\hline Harmonia & Tema & Compassos & Região \\
\hline $\mathrm{bb}$ & \multirow{3}{*}{1} & 50 a 55 & $\mathrm{sm}$ \\
\hline caminhando para f\# & & 52 a 54 & $\mathrm{m \#}$ \\
\hline $\mathrm{f \#}$ & & 55 a 57 & $\mathrm{m \#}$ \\
\hline instável (f\#-A) & J & 58 a 62 & $\mathrm{x}$ \\
\hline Instável (atonal) & $\mathrm{K}(\mathrm{C})$ & 63 a 66 & $x$ \\
\hline Instável (flerte com Db) & I1 (motivo inicial) & 67 a 68 & $x$ \\
\hline f & $K(C)+I$ & 69 a 71 & $\mathrm{mb}$ \\
\hline \multirow[t]{2}{*}{ Instável (Ab-Db-F-ab) } & $\mathrm{J}+\mathrm{K}(\mathrm{C})$ & 71.5 a 74 & $x$ \\
\hline & $\mathrm{L}$ & 75 a 76 & $\mathrm{vmb}$ \\
\hline g & $\mathrm{L}$ & 77 a 78 & sd \\
\hline Db (instável no final) & $M(C)$ & 79 a 80 & $x$ \\
\hline eb & $\mathrm{L}$ & 83 a 84 & mvmb \\
\hline $\mathrm{bb}$ & $\mathrm{L}$ & 85 a 86 & $\mathrm{sm}$ \\
\hline E (instável no final) & $M(C)$ & 87 a 90 & $x$ \\
\hline $\mathrm{f}$ & $\mathrm{L}$ & 91 a 92 & $m b$ \\
\hline$c$ & $\mathrm{~L}$ & 93 a 97 & $\mathrm{vmb}$ \\
\hline $\begin{array}{l}\text { Instável (f-E por meio da } \\
\text { dominante da dominante } \\
\text { - modulação enarmônica) }\end{array}$ & I & 98 a 99 & $x$ \\
\hline
\end{tabular}

Fonte: elaboração do autor

Neste trecho da peça que vai do compasso 1 até o compasso 99, e com exceção do tema D, em Fá maior, ocorre um predomínio quase total de tonalidades em modo menor. A maior parte destas regiões se situa no lado descendente do ciclo das quintas, ou seja, no lado da subdominante. O compasso 100 inaugura a terceira parte da peça com um tema em Mi maior, o que chama a atenção não apenas pelo contraste de modo, mas também porque esta região é a primeira região harmônica relevante situada no lado ascendente do 
ciclo das quintas, o lado da dominante ${ }^{9}$. Note-se ainda que o tema A é sugerido sutilmente em alguns momentos, em meio a outros materiais temáticos, mas não se constitui como um retorno claro do tema, como mencionamos antes. $\mathrm{O}$ momento que vai do compasso 122 ao 168 possui um caráter harmônico instável e duradouro, à maneira de um desenvolvimento tonal:

Quadro 8: Análise formal da terceira parte da Noite Transfigurada.

\begin{tabular}{|c|c|c|c|}
\hline Harmonia & Tema & Compassos & Região \\
\hline E & $\mathrm{N}$ & 100 a 104 & $\mathrm{~S} / \mathrm{T}$ \\
\hline E (lídio) & $\mathrm{O}$ & 105 a 110 & $\mathrm{~S} / \mathrm{T}$ \\
\hline instável (em torno de E) & $\mathrm{M}(\mathrm{C})$ & 111 a 112 & $x$ \\
\hline $\mathrm{E}$ & $\mathrm{O}$ & 115 a 118 & $\mathrm{~S} / \mathrm{T}$ \\
\hline C & Final de $N+A$ inv & 119 a 121 & $\mathrm{DMb}$ \\
\hline Instável (F-Ab-bb) & $M+A$ inv & 122 a 123 & $x$ \\
\hline Instável & $\mathrm{L}+\mathrm{M}+(\mathrm{I}$ no final $)$ & 124 a 131 & $x$ \\
\hline Instável & material textural introdutório & 132 a 137.8 & $x$ \\
\hline instável (f-ab) & $\mathrm{P}$ & 137.8 a 140 & $x$ \\
\hline Instável (flerte com bb) & 1 & 141 a 143 & $x$ \\
\hline instável & material textural introdutório & 144 a 146 & $x$ \\
\hline instável & $E+P$ & 147 a 149 & $x$ \\
\hline Instável & 1 & 150 a 152 & $x$ \\
\hline Instável & $\mathrm{P}$ & 153 a 168 & $x$ \\
\hline Eb & $\mathrm{N}$ & 169 a 174 & $\mathrm{~Np}$ \\
\hline $\mathrm{Ab} / \mathrm{ab}$ & $\mathrm{F}$ & 175 a 180 & SMSM/smSM \\
\hline Instável (sugerindo d) & $\mathrm{E}$ & 181 a 187 & $\mathrm{x}$ \\
\hline Instável (sugerindo d) & $Q(J)$ & 188 a 200 & $x$ \\
\hline Instável & $A+Q$ & 201 a 211 & $x$ \\
\hline$F / f$ & $A+D$ & 212 a 218 & $\mathrm{M}$ \\
\hline $\mathrm{eb}$ & $G$ & 219 a 228 & $m v m b$ \\
\hline
\end{tabular}

Fonte: elaboração do autor

$\mathrm{Na}$ quarta parte da peça ocorre um retorno à tônica, agora em modo maior. A harmonia ainda se movimenta bastante entre regiões harmônicas distintas, sobretudo para as regiões de antirrelativa maior da tônica maior (Fá\# maior, mediante), no início do

\footnotetext{
${ }^{9}$ Em The Classical Style, Charles Rosen expõe os princípios fundamentais do tonalismo clássico por meio de asserções teóricas. Em determinado momento, o autor diferencia a função das regiões situadas no lado descendente do ciclo das quintas, que seria relativa à função harmônica de subdominante, da função das regiões situadas no lado ascendente do ciclo, aparentadas à função de dominante e, portanto, mais afirmativas da tônica (ROSEN, 1998, p. 25-7).
} 
trecho, e de relativa maior da tônica menor (Fá maior, também uma mediante), mais adiante. A região de Réb maior também é bastante valorizada, sobretudo no compasso 320 , em que ela surge no lugar do que parecia ser um retorno à tônica.

Como se pode observar pela figura abaixo, a escuta da dominante de Ré (Lá Maior) - em uma das raras vezes em que é colocada com clareza pelo compositor - dá a entender que se seguirá uma reexposição da tonalidade principal (Ré), entretanto, o retorno da tônica é retardado pela ocorrência de um trecho na tonalidade de Réb que antecede (e valoriza) o retorno triunfal da tônica 16 compassos depois (e que agora permanece incólume até o final). Segundo Shawn (2003, p. 20) "estas modulações ocorrem através de 'armadilhas musicais' perfeitamente naturais, embora nunca antes ouvidas":

Figura 7: modulação surpreendente para Réb maior (compassos 319-320).

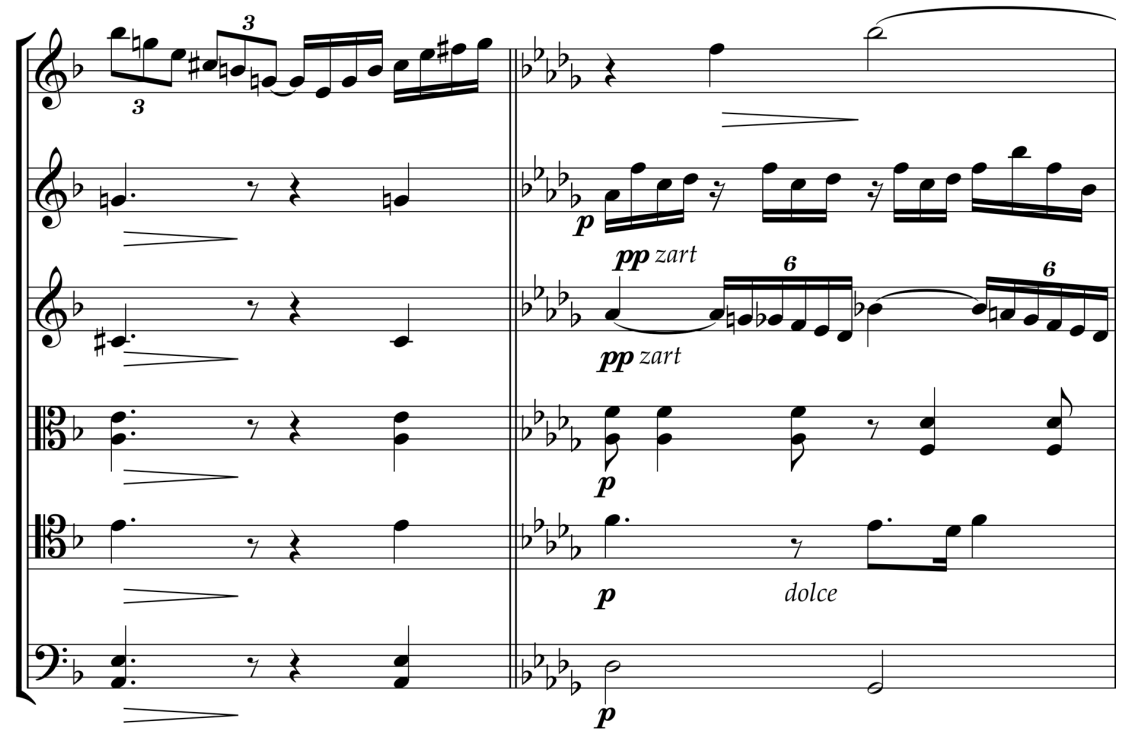

Fonte: elaboração do autor

Nesta parte da peça predominam as tonalidades em modo maior intercaladas com momentos de instabilidade harmônica. Além disso, Schoenberg expõe cinco novos temas musicais. A figura abaixo ilustra estas relações detalhadamente:

Quadro 9: Análise formal da quarta parte da Noite Transfigurada.

\begin{tabular}{|c|c|c|c|}
\hline Harmonia & Tema & Compassos & Região \\
\hline D & R & 229 a 233 & T \\
\hline F\# & R & 234 a 235 & M\# \\
\hline
\end{tabular}




\begin{tabular}{|c|c|c|c|}
\hline D & $\mathrm{E}$ & 236 a 239 & $\mathrm{~T}$ \\
\hline F\# & $\mathrm{E}$ & 240 a 243 & $\mathrm{M} \#$ \\
\hline $\begin{array}{c}\text { Instável (flerte com várias } \\
\text { regiões e sugerindo D ao } \\
\text { final) }\end{array}$ & Final de $N+A$ inv & 244 a 248 & $x$ \\
\hline F\# & $S$ & 249 a 258 & $\mathrm{M \#}$ \\
\hline F\# & $\mathrm{T}$ & 259 a 265 & $\mathrm{M \#}$ \\
\hline $\mathrm{eb}$ & $A+I$ variado & 266 a 269 & $m v m b$ \\
\hline Db (pedal dominante) & $\begin{array}{c}\mathrm{A}+\mathrm{I} \text { variado (outra variação } \\
\text { em maior) }\end{array}$ & 270 a 273 & $\mathrm{SMS} / \mathrm{T}$ \\
\hline Instável (em torno de Db) & $\mathrm{A}+\mathrm{I}+\mathrm{M}$ & 274 a 276 & $x$ \\
\hline Db (pedal dominante) & U & 277 a 282 & $\mathrm{SMS} / \mathrm{T}$ \\
\hline instável (Db-eb) & $U$ & 283 a 290 & $x$ \\
\hline $\mathrm{F}$ & $U$ & 291 a 293 & $\mathrm{M}$ \\
\hline F & F em maior & 294 a 295 & $\mathrm{M}$ \\
\hline F & $U$ & 296 a 297 & M \\
\hline $\mathrm{F}$ & $\mathrm{N}+\mathrm{U}$ & 297 a 298 & $\mathrm{M}$ \\
\hline $\mathrm{F}$ & $\mathrm{F}$ & 299 a 301 & $\mathrm{M}$ \\
\hline Instável & $\mathrm{N}$ & 302 a 309 & $x$ \\
\hline Instável & $A+F+N+P$ & 310 a 313 & $x$ \\
\hline Instavel (sugerindo D) & $\mathrm{A}+\mathrm{F}+\mathrm{N}+\mathrm{P}$ & 314 a 319 & $x$ \\
\hline Db (com transição para D) & $\mathrm{x}$ & 320 а 336 & $\mathrm{SMS} / \mathrm{T}$ \\
\hline
\end{tabular}

Fonte: elaboração do autor

A partir do compasso 337, a tônica retorna em caráter definitivo e ocupa praticamente toda a duração da parte final da Noite Transfigurada. Se, do ponto de vista da harmonia, a reexposição da tônica é explícita, do ponto de vista do agenciamento dos materiais temáticos esta é a única parte da obra que não apresenta novos temas, apenas retrabalha aqueles que haviam sido apresentados anteriormente. A única exceção é o momento final, a Coda que se inicia no compasso 407, que se baseia em um material textural novo. Além disso, a memória do tema $\mathrm{A}$ é retomada à medida em que o tema é reapresentado em primeiro plano na região da tônica, Ré Maior, nos trechos que abrangem os compassos 370-90 e 401-6.

Quadro 10: Análise formal da quinta parte da Noite Transfigurada.

\begin{tabular}{|c|c|c|c|}
\hline Harmonia & Tema & Compassos & Região \\
\hline D & variação de X & $337-340$ & $\mathrm{~T}$ \\
\hline D & $\mathrm{R}+\mathrm{U}$ & 341 a 344 & $\mathrm{~T}$ \\
\hline
\end{tabular}




\begin{tabular}{|c|c|c|c|}
\hline D/d & Fim de N & 345 347 & $\mathrm{T}$ \\
\hline D & Fim de D & 348 a 355 & $\mathrm{T}$ \\
\hline D & U variado & $356-362$ & $\mathrm{~T}$ \\
\hline D & M variado (aumentado) & 363 a 369 & $\mathrm{T}$ \\
\hline D & G cadência/coral & 366 a 369 & $\mathrm{T}$ \\
\hline D & $\mathrm{A}$ & $370-390$ & $\mathrm{~T}$ \\
\hline F & $\mathrm{F}$ & 376 a 377 & $\mathrm{M}$ \\
\hline Instável & $\mathrm{T}$ & 378 a 390 & $\mathrm{X}$ \\
\hline D & $\mathrm{X}$ & $391-393$ & $\mathrm{~T}$ \\
\hline Instável & G cadência/coral & 394 a 396 & $\mathrm{x}$ \\
\hline $\mathrm{D}$ & U variado & 397 a 400 & $\mathrm{T}$ \\
\hline D & $\mathrm{A}$ & 401 a 406 & $\mathrm{T}$ \\
\hline D & Coda (material textural novo) & 407 ao fim & $\mathrm{T}$ \\
\hline
\end{tabular}

Fonte: elaboração do autor

\section{Considerações a partir da análise da estrutura formal da Noite Transfigurada}

Através do exame das relações microestruturais apresentadas acima, é possível observar a existência de um plano harmônico geral em que a tônica é rodeada pelas tonalidades situadas um semitom acima e abaixo (Mib/Réb). O mesmo ocorre com outras regiões importantes como as regiões de iv, v e III graus. Vale notar que estas são as primeiras regiões apresentadas na peça. Como já foi dito, apesar do alto cromatismo que caracteriza diversos momentos da obra, na maior parte das vezes é possível determinar claramente os centros tonais e perceber sua contraposição a momentos de maior instabilidade harmônica, que funcionam muitas vezes como transição entre as partes estáveis, ou seja, entre regiões temáticas.

Uma das primeiras coisas que chama a atenção em relação ao planejamento harmônico da peça é que a dominante, embora esteja presente como uma força relevante na peça, não surge como região harmônica em nenhum momento ${ }^{10}$, algo que foi, aliás, observado nos trabalhos de Swift (1977) e Frisch (1993). As principais regiões de contraste à tônica ocorrem com as seções em Fá maior, relativa da tônica menor, e Mi maior, supertônica.

\footnotetext{
${ }^{10}$ Embora haja uma seção em lá menor, quinto grau menor, no início da peça, como foi dito anteriormente.
} 
A partir do exame das regiões harmônicas na peça, não é difícil perceber as razões que levaram Swift e Pfannkuch a analisarem a Noite Transfigurada como uma sonata. Existe um paralelo claro entre a trajetória harmônica da forma-sonata e a trajetória harmônica da Noite Transfigurada. Seria possível interpretar a exposição como sendo formada por um conjunto de temas A entre o compasso 1 ao 40 e um conjunto de temas B conectados por pontes de 41 a 121; um desenvolvimento permeado por alguns episódios estáveis em regiões em geral distantes da tônica de 122 a 228; e, finalmente, uma reexposição de 229 ao fim, que contém um desenvolvimento secundário entre os compassos 244 e 336.

Ainda assim, este paralelo ocorre à custa de uma certa simplificação das nuances microestruturais estabelecidas na obra. A multiplicidade de ideias e seções ainda reguladas pela harmonia tonal fazem com que a peça, do ponto de vista formal, se aproxime mais de um Rondó Mozartiano do que do esquema formal de uma sonata clássica preconizado por A. B. Marx. Observe-se, por exemplo, a forma do Andante do Concerto para Piano $n^{\circ} 17$ :

Quadro 11: Análise formal do Andante do Concerto nº17 para piano de Mozart.

\begin{tabular}{|c|c|c|c|c|}
\hline \multirow{7}{*}{$\begin{array}{l}\text { Função } \\
\text { Tema }\end{array}$} & Subseção & Tamanho & Região & Parte \\
\hline & a & $5 c$. & C & \multirow{5}{*}{$A$} \\
\hline & $b$ & 13c. & C & \\
\hline & C & 8c. & C & \\
\hline & $d$ & $5 c$. & $\mathrm{C}(\mathrm{Cm})$ & \\
\hline & a & $5 c$. & C & \\
\hline & e & $8 c$. & $\mathrm{Gm}$ & \multirow{5}{*}{ B } \\
\hline \multirow[t]{2}{*}{ Instável (transição) } & $f(b)$ & 11c. & G (Inst.) & \\
\hline & $d^{\prime}$ & $5 c$. & $\mathrm{Gm}$ & \\
\hline \multirow[t]{2}{*}{ Transição } & $g(b)$ & 7c. & G & \\
\hline & a & $5 c$. & G & \\
\hline \multirow{3}{*}{$\begin{array}{l}\text { Episódio } \\
\text { Instável (transição) } \\
\text { Instável (transição) }\end{array}$} & h (e) & $6 c$. & $\mathrm{Dm}$ & \multirow{3}{*}{$\begin{array}{c}\mathrm{C} \\
\left(\mathrm{B}^{\prime}\right)\end{array}$} \\
\hline & $\mathrm{i}(\mathrm{d})$ & 9c. & $\mathrm{Dm}-(\mathrm{F \#})$ & \\
\hline & j & $5 c$. & $(G \#)-C$ & \\
\hline \multirow[t]{4}{*}{ Tema } & a & $5 c$. & C & \multirow[t]{4}{*}{ A } \\
\hline & $e^{\prime}$ & 8c. & $\mathrm{Eb}$ & \\
\hline & $f^{\prime}(b)$ & 10c. & $\mathrm{C}$ & \\
\hline & $c^{\prime}$ & 12c. & C & \\
\hline
\end{tabular}




\begin{tabular}{|l|l|l|l|}
\hline $\mathrm{a}$ & 5c. & $\mathrm{C}$ & \\
\cline { 1 - 3 } $\mathrm{k}$ & 3c. & $\mathrm{C}$ & \\
\hline $\mathrm{d}^{\prime}$ & 6c. & $\mathrm{C}$ & \\
\hline
\end{tabular}

Fonte: elaboração do autor

O Andante do Concerto para piano 17 de Mozart também lida com uma alta quantidade de temas regulados por uma harmonia tonal. Um tema a (refrão) é rememorado após ser contrastado a outros temas (copla), como ocorreria em um rondó e, ainda assim, a harmonia agrupa estes materiais temáticos em três grandes partes à maneira de uma forma-sonata: uma exposição em que a tônica é afirmada nos primeiros 34 compassos e contraposta à uma região na dominante (até o compasso 68); um desenvolvimento, mais curto, que começa com um episódio na região de subdominante relativa (cs. 69-74) seguido por um momento de grande instabilidade harmônica que inclui a passagem pelas regiões de submediante maior da submediante maior (Fá\#) e mediante maior da mediante maior (Sol\#); finalmente, uma reexposição da tonalidade, e do tema (cs. 90 ao fim), intercalada por um episódio em Mib, relativa maior da tônica menor.

Quando reunimos as peças de Schoenberg e de Mozart com o primeiro movimento da Phantasie op. 17 de Schumann (ver tabela abaixo) e observamos a relação entre a forma e a harmonia, é possível percebermos uma transição gradual em direção à complexidade estrutural, em uma escala que vai do Andante de Mozart, passa pela Phantasie de Schumann, até finalmente chegar na Verklärte Nacht.

Quadro 12: Esquema formal do primeiro movimento da Phantasie op. 17 de Schumann.

\begin{tabular}{|c|c|c|c|c|c|}
\hline Parte & Função & Tom & Tamanho & Compasso & Seção \\
\hline $\mathbf{a}$ & Tema A & $\mathrm{C}$ & 14 & 1 & \multirow{8}{*}{$\mathrm{A}$} \\
\hline b & Tema A' e contraste & G & 5 & 14 & \\
\hline $\mathbf{a}^{\prime}$ & Tema A & $\mathrm{C}$ & 9 & 19 & \\
\hline$a^{\prime \prime}$ & Tema A & $\mathrm{Eb}$ & 5 & 28 & \\
\hline c (b) & Tema B & $\mathrm{cm} \rightarrow \mathrm{dm}$ & 8 & 33 & \\
\hline d (a) & Tema A " & $\mathrm{dm}$ & 8 & 41 & \\
\hline $\mathbf{b}^{\prime}$ & Tema $A^{\prime}$ & $\mathrm{dm}$ & 4 & 49 & \\
\hline e & Ponte & $\mathrm{dm} \rightarrow \mathrm{F}$ & 8 & 53 & \\
\hline
\end{tabular}




\begin{tabular}{|c|c|c|c|c|c|}
\hline $\mathbf{d}^{\prime}$ & Tema A " & $\mathrm{F}$ & 8 & 61 & \\
\hline $\mathbf{b}^{\prime \prime}$ & Tema A' & $\mathrm{F}$ & 4 & 69 & \\
\hline $\mathbf{f}$ & Coda & $\mathrm{Bb} \rightarrow \mathrm{dm}$ & 9 & 73 & \\
\hline $\mathbf{g}$ & $\begin{array}{c}\text { Ponte de volta para } \\
\text { Dó }\end{array}$ & Instável (ciclo $\left.5^{\mathrm{a}} \mathrm{s}\right)$ & 16 & 82 & \\
\hline$a^{\prime \prime \prime}$ & Tema A & $\mathrm{C}$ & 8 & 97 & \\
\hline $\mathbf{h}$ & Seção contrastante & $\mathrm{C} \rightarrow \mathrm{Eb}$ & 14 & 105 & \\
\hline$a^{\prime \prime \prime \prime}$ & Tema A & $\mathrm{C}$ & 10 & 119 & \\
\hline $\mathbf{c}^{\prime}$ & Tema B & $\mathrm{gm}$ & 4 & 128 & \multirow{8}{*}{$\mathrm{B}$} \\
\hline$c^{\prime \prime}$ & Tema B & $\mathrm{cm}$ & 24 & 133 & \\
\hline i (b) & Seção contrastante & $\mathrm{cm}$ & 17 & 156 & \\
\hline$c^{\prime \prime \prime \prime}$ & Tema B & $\mathrm{cm}$ & 7 & 173 & \\
\hline$d^{\prime \prime}$ & Tema A " & $\mathrm{Db} \rightarrow \mathrm{cm}$ & 14 & 181 & \\
\hline $\mathbf{j}$ & Ponte & $\mathrm{cm}$ & 9 & 195 & \\
\hline$c^{\prime \prime \prime \prime \prime}$ & Tema B & $\mathrm{fm}$ & 12 & 204 & \\
\hline$c^{\prime \prime \prime \prime \prime \prime}$ & Tema B & $\mathrm{cm}$ & 9 & 216 & \\
\hline$a^{\prime \prime \prime \prime}$ & Tema A & $\mathrm{Eb}$ & 5 & 224 & \multirow{11}{*}{$\mathrm{A}^{\prime}$} \\
\hline$c^{\prime \prime \prime \prime \prime \prime \prime}$ & Tema B & $\mathrm{cm}$ & 3 & 230 & \\
\hline$d^{\prime \prime \prime}$ & Tema A " & $\mathrm{cm}$ & 8 & 233 & \\
\hline$b^{\prime \prime \prime}$ & Tema $A^{\prime}$ & $\mathrm{cm}$ & 4 & 241 & \\
\hline $\mathbf{e}^{\prime}$ & Ponte & $\mathrm{cm}$ & 8 & 245 & \\
\hline$d^{\prime \prime \prime \prime}$ & Tema A " & $\mathrm{Eb}$ & 8 & 253 & \\
\hline$b^{\prime \prime \prime \prime}$ & Tema A' & $\mathrm{Eb}$ & 4 & 261 & \\
\hline $\mathbf{f}^{\prime}$ & Coda & $\mathrm{Ab} \rightarrow \mathrm{cm}$ & 9 & 265 & \\
\hline$g^{\prime}$ & $\begin{array}{c}\text { Ponte de volta para } \\
\text { Dó }\end{array}$ & Instável (ciclo $\left.5^{\mathrm{a}} \mathrm{s}\right)$ & 12 & 273 & \\
\hline$a^{\prime \prime \prime \prime \prime}$ & Tema A & $\mathrm{C}$ & 10 & 285 & \\
\hline $\mathbf{k}$ & Citação & $\mathrm{C}$ & 14 & 294 & \\
\hline
\end{tabular}

Fonte: elaboração do autor

Neste sentido, a declaração de Webern de que a Noite Transfigurada possuiria a forma de uma livre fantasia pode parecer adequada para descrever a peça de Schoenberg, desde que se ressalve que uma fantasia, uma vez materializada em som, também possui uma forma, ainda que não se conforme em modelos pré-estabelecidos e ensinados como regra em conservatórios. 


\title{
Considerações Finais
}

A partir das últimas considerações acima, fica aparente como a forma da Noite Transfigurada se coloca como a etapa derradeira do desenvolvimento de uma relação cada vez mais complexa entre a harmonia e a forma no Romantismo, ou, ao menos, em relação àquelas inseridas na tradição do Romantismo germânico. Em um artigo anterior, analisando a peça opus 33b, também de Schoenberg, escrevi as seguintes palavras:

\begin{abstract}
Em um primeiro contato com a obra, ficam evidentes as dificuldades de segmentação formal e estabelecimento de relações dos materiais musicais que se colocam para a percepção. São muitos os desafios que se colocam para a escuta: a peça apresenta uma alta densidade de ideias que se sucedem rapidamente; existe, como dissemos, um cromatismo intenso que dificulta, a princípio, que o ouvinte se situe harmonicamente com relação à forma musical; e, por diversas vezes, materiais de diversas seções são apresentados simultaneamente, de maneira extremamente polifônica, o que dificulta ainda mais a segmentação formal (RODRIGUES, 2019, p. 9).
\end{abstract}

Estas linhas serviriam perfeitamente para descrever a forma da Noite Transfigurada, com uma diferença: enquanto na peça opus $33 \mathrm{~b}$ as informações resultantes da inter-relação entre os parâmetros sonoros se colocam em primeiro plano a partir da escuta das relações motívicas e temáticas, que atuam como principais elementos redundantes, na Noite Transfigurada a harmonia ainda é uma força relevante de estruturação frente à escuta. Ela ainda cumpre um papel essencial na diferenciação das partes, estabelecendo suas funções na forma total. Em outras palavras, existe um projeto harmônico em que ainda se percebe a existência dos mecanismos fundamentais do tonalismo, responsáveis pelo aumento da redundância das relações internas colocadas pela obra nos planos micro e macro estruturais.

Por maiores que sejam as diferenças das propostas de segmentação formal dos trabalhos discutidos anteriormente, no geral eles estão ancorados em dados comprováveis materialmente no discurso sonoro da peça. Em relação à visão que relaciona a estruturação da peça com a forma-sonata, o que parece evidente após uma incursão detalhada aos meandros das relações harmônicas é que a forma-sonata se reporta à Noite Transfigurada na mesma medida em que a forma-sonata se configura como uma expressão da relação entre forma e harmonia no tonalismo de modo geral. Em outras palavras, a relação entre a Noite Transfigurada e a forma-sonata é semelhante à relação 
entre a forma-sonata e qualquer outra peça tonal, no sentido que ela atua como expressão máxima do desenvolvimento da relação entre harmonia e forma no tonalismo.

De alguma maneira, a estrutura da peça se reporta diretamente à estrutura do poema, inclusive no que se refere às suas ambiguidades. Assim como no poema, ela pode ser subdividida em cinco grandes partes, análogas às estrofes (como propusemos no decorrer deste texto), mas também poderia ser subdividida em duas partes, assim como o poema, sendo a primeira parte correspondente aos compassos 1 a 228 , em que predominam tonalidades menores, e a segunda aos compassos 229 ao fim, em que predominam as tonalidades maiores.

Quanto aos elementos temáticos, o que se percebe é que as repetições, mesmo na forma de variações próximas, são extremamente raras. A memória se coloca quase sempre através do processo de liquidação motívica e variação em desenvolvimento. Ao mesmo tempo em que quase nada se repete literalmente, todos os elementos parecem ser construídos uns a partir dos outros. Ainda que seja uma característica presente em diversas obras do compositor, esta estratégia de não repetir os temas, mas conectá-los através de elementos comuns que vão sendo variados pouco a pouco, se adequa perfeitamente ao conteúdo semântico e à estruturação da poesia de Dehmel: os temas musicais vão se transfigurando à medida em que a música avança...

\section{Referências}

CUETO JÚNIOR, Amâncio. Noite Transfigurada - Parte VI. 2017. Disponível em: < http://euterpe.blog.br/noite-transfigurada-parte-vi/>. Acesso em: 16/10/2021.

DAHLHAUS, Carl. Schoenberg and Programme Music. In: Schoenberg and the New Music, p. 94-104. Cambridge: Cambridge University Press, 1987.

EASON, Andrew C. Formal Functions in the Music of Arnold Schoenberg. Tese (Doutorado em Filosofia). Oregon: University of Oregon, 2019.

FRISCH, Walter. The Early Works of Arnold Schoenberg, 1893-1908. L.A: University of California Press, 1993.

HAIMO, Ethan. Developing variation and Schoenberg's serial music. In: Musical Analysis, vol. 16, n. 3, p. 349-365, 1997.

HAUPTMANN, Moritz. The nature of harmony and metre - primary source edition. Charleston: Nabu Press, 2014. 
MUXENEDER, Therese. Introduction. 2021. Disponível em: $<$ https://www.schoenberg.at/index.php/en/joomla-license-3/rverklaerte-nachtl-sextett-fuer-2violinen-2-violen-und-2-violoncelli-op-4-1899>. Acesso em: 16/10/2021.

PEDNEAULT-DESLAURIERS, Julie. Dominant Tunnels, Form and Program in Schoenberg's Verklârte Nacht. In: Formal Functions in Perspective: Essays on Musical Form from Haydn to Adorno. editado por Steven Vande Moortele, Julie Pedneault-Deslauriers, Nathan John Martin) e Walter Bailey. Rochester: University of Rochester Press, 2015.

PFANNKUCH, Wilhelm. Zu Thematik und Form in Schönbergs Streichsextett. In: Festschrift Friedrich Blume: Zum 70. Geburtstag, p. 258- 71. Kassel: Bärenreiter, 1963.

RIEMANN, Hugo. The Nature Of Harmony. [s.1.] Ed. T. Presser, 1886.

ROSEN, Charles. The Classical Style: Haydn, Mozart, Beethoven. New York: W. W. Norton, 1998.

SCHOENBERG, Arnold. Funções Estruturais da Harmonia. São Paulo: Eduardo Seincman, 2011.

SCHOENBERG, Arnold. Konstruktives in der Verklärten Nacht. Barcelona, 1932. Disponível em: $\quad<$ https://www.schoenberg.at/index.php/de/natur-online/1668-objekt6>. Acesso em: $16 / 10 / 2020$.

SCHOENBERG, Arnold. Schoenberg's Program Notes and Musical Analyses. Oxford: Oxford University Press, 2016.

SCHOENBERG, Arnold. Letters. Selecionadas e editadas por Erwin Stein. Traduzidas por Eithne Wilkins e Ernst Kaiser. London: Faber \& Faber, 1964.

SCHOENBERG, Arnold. Style and idea: selected writings of Arnold Schoenberg. Los Angeles: University of California Press, 1984.

SCHOENBERG, Arnold. In: The Hollywood String Quartet plays Schoenberg and Schubert. LP, SBT: 1031. Arnold Schoenberg (Compositor). Hollywood String Quartet: Felix Slatkin (intérprete, violino), Paul Shure (intérprete, violino), Paul Robyn (intérprete, viola) Eleanor Aller (intérprete, violoncelo) com Alvin Dinkin (intérprete, viola) Kurt Reher (intérprete, violoncelo). Los Angeles: Testament, 1950.

SHAWN, Allen. Arnold Schoenberg's Journey. New York: Farrar, Straus and Giroux, 2003.

SWIFT, Richard. "1/XII/99: Tonal Relations in Schoenberg's Verklärte Nacht." 19th-Century Music 1. 3-14, 1977.

STUCKENSCHMIDT, Hans Heinz. Schoenberg: His Life, World and Work. [S.1.]: Schirmer Books, 1978.

WEBERN, Anton. "Schönbergs Musik”. In Arnold Schönberg, Munich: Piper, 1912. 22- 48.

WELLESZ, Egon. 1925. Arnold Schoenberg. New York: Da Capo Press, 1969. 